\title{
STRATEGI PENGELOLAAN HUTAN RAKYAT DI KABUPATEN MAROS
}

\author{
Community Forest Management Strategy in Maros District \\ Muhammad Yusuf ${ }^{1}$, St. Subaedah ${ }^{2}$, Saida $^{2}$ \\ ${ }^{1}$ Mahasiswa Program Studi Magister Agroekoteknologi \\ ${ }^{2}$ Dosen Fakultas Pertanian Universitas Muslim Indonesia, Makassar. \\ muhyusufantang@gmail.com st.subaeda@umi.ac.id saida.saida@umi.ac.id
}

\begin{abstract}
This study aims to determine external and internal factors in community forest management in Maros Regency, formulate community forest development strategies through involvement with stakeholders in Maros Regency and to analyze steps that need to be used as a reference and policy recommendation for community forest management in the Regency. Maros. Data retrieval in this study was carried out by a survey method which was conducted with a questionnaire for business actors or farmer groups, while interviews were for agricultural and forestry extension agents, including the village government. The sample was determined by purposive sampling by determining 50 respondents of community forest management farmers. Each of 25 people per district, each sub-district is represented by 5 groups and 1 group consisting of 5 people, namely the Chairperson, Secretary, Treasurer plus 2 members. The analysis used in this research is descriptive statistical analysis, SWOT analysis (strength, weakness, opportunity, threat). The results of the analysis show that there are two strategic priorities that can be applied, namely (1) strengthening the role of the group by providing accurate market information; (2) provide forestry counseling and guidance from the government for area arrangement and management plan preparation; (3) The government facilitates licensing to establish a timber industry in order to increase the value price of wood; and (4) Using agroforestry patterns.
\end{abstract}

Keywords : Strategy; Management; Forest; Community Forest

PENDAHULUAN

Indonesia mempunyai hutan tropis dengan luas terbesar ketiga setelah Brazil dan Zaire, sehingga memiliki tanggung jawab dalam melestarikan agar tetap dapat berfungsi sebagai paru-paru dunia. Fungsi hutan menurut Suparmoko (1997) di antaranya adalah mengatur tata air, mencegah dan membatasi banjir, erosi, serta memelihara kesuburan tanah; menyediakan hasil hutan untuk keperluan masyarakat pada umumnya dan khususnya untuk keperluan pembangunan industri dan ekspor sehingga menunjang pembangunan

ekonomi; melindungi suasana iklim dan memberi daya pengaruh yang baik; memberikan keindahan alam pada umumnya dan khususnya dalam bentuk cagar alam, suaka margasatwa, taman perburuan, dan taman wisata, serta sebagai laboratorium untuk ilmu pengetahuan, pendidikan, dan pariwisata; serta merupakan salah satu unsur strategi pembangunan nasional.

Pasokan bahan baku dari hutan alam yang terus menurun, dapat dilihat 
sebagai peluang untuk mendorong upaya pengembangan hutan rakyat di luar kawasan hutan negara. Potensi pengembangan dan keberhasilan pembangunan hutan rakyat ini, akan sangat bergantung pada kesiapan aparat pemerintah pusat maupun daerah dan masyarakat, yaitu petani dan industri kayu (Sukadaryati, 2006). Pengembangan hutan rakyat, memiliki potensi yang cukup untuk pengembalian fungsi lingkungan (ekologis) maupun ekonomis, sehingga perlu didukung oleh aturan-aturan yang jelas.Selanjutnya aturan-aturan tersebut sebagai pegangan bagi para pihak (stakeholders) yang terlibat di dalam pengembangan hutan rakyat.Sebagai landasan yuridis, aturanaturan dimaksud diharapkan dapat menjadi payung hukum yang efektif dan efisien.

Potensi hutan rakyat di Indonesia sangat besar, luasnya mencapai 1.271.505,61 ha, di Sulawesi Selatan luasnya 228,345.90 ha, dan di Kabupaten Maros luasnya 9,732.00 ha (BPS, 2017). Adapun jenis tanaman yang paling banyak ditanam di hutan rakyat Kabupaten Maros adalah diantaranya adalah : Tectona grandis (Jati lokal), Ghamelina arborea (Jati Putih), Mahoni, Jabon, Kemiri, Bambu, Mangga, Jambu Mente, Cacao, Kapok atau
Randu. Dengan melihat Luas Hutan rakyat yang tersebar merata hampir pada semua kecamatan di Kabupaten Maros. Hal tersebut merupakan indikasi bahwa hutan rakyat di Kabupaten Maros bisa memberikan kontribusi hasil hutan rakyat baik itu berupa kayu ataupun hasil hutan ikutan. Walaupun masih ada beberapa kecamatan dari 14 kecamatan yang belum mengelolah hutan rakyat dan ini merupakan tantangan bagi pengurus Kelompok Tani, Pemerintah termasuk penyuluh bagaimana mereka bisa memanfaatkan potensi yang ada.

Penyusunan rumusan strategi pengelolaan hutan rakyat melalui keterlibatan bersama pemangku kepentingan, berdasarkan potensi dan problematika pengelolaan hutan rakyat yang diprioritaskan pada kriteria yang paling dominan, yaitu dari aspek lingkungan, aspek ekonomi dan aspek sosial. Petani sebagai salah satu pemangku kepentingan dapat mengemukakan pendapat atas potensi dan problematika pengelolaan hutan rakyat yang dihadapi, dan dapat ikut serta dalam mengambil keputusan secara bersama 
dengan tokoh yang berpengalaman dalam Maros dengan 2 sampel kecamatan yaitu bidang pengelolaan hutan rakyat serta Kecamatan Moncongloe dan Kecamatan pejabat tingkat desa sampai tingkat Cenrana.

kabupaten. Oleh karena itu dalam penelitian ini, peneliti menempatkan petani sebagai

Jenis dan Sumber Data

subyek sekaligus obyek dalam pengelolaan hutan rakyat. Berdasarkan uraian tersebut, maka pendekatan strategi pengelolaan hutan rakyat sebagai bagian pemanfaatan lahan sangat relevan seiring dengan semakin lajunya degradasi hutan. Aadapun tujuan dari penelitian ini adalah:

1. Mengidentifikasi faktor-faktor eksternal dan internal dalam pengelolaan hutan rakyat di Kabupaten Maros.

2. Merumuskan strategi pembangunan hutan rakyat melalui keterlibatan bersama pemangku kepentingan di Kabupaten Maros.

3. Menganalisis langkah-langkah yang perlu dijadikan acuan dan rekomendasi kebijakan pengelolaan hutan rakyat di Kabupaten Maros

\section{METODE PENELITIAN}

Penelitian ini berlangsung selama tiga bulan yang dimulai pada bulan Januari sampai dengan bulan Maret Tahun 2020. Penelitian dilaksanakan di Kabupaten

Data yang dikumpulkan terdiri dari data primer dan sekunder.Data primer diperoleh melalui wawancara langsung dengan responden petani di sekitar hutan rakyat.Sedangkan data sekunder diperoleh dari pemerintah desa instansi lembaga terkait, Penyuluh Kehutanan dan Penyuluh Pertanian.

\section{Teknik Pengumpulan Data dan Jenis Data}

Responden dari penelitian ini adalah petani yang mengelolah hutan rakyat dan wakil dari Pemerintah yang mengetahui program hutan rakyat.Pengambilan sampel dilakukan secara sengaja purposive sampling dengan pertimbangan bahwa responden mengetahui program hutan rakyat. Responden terdiri dari (1) Kelompok Tani Hutan, (2) Penyuluh Pertanian dan penyuluh Kehutanan (3) Pemerintah Desa

\section{Populasi dan sampel}

Penentuan sampel dilakukan dengan cara Purposive sampling dengan menentukan 50 orang responden petani pengelolah hutan rakyat. Masing masing 25 
orang per kecamatan, setiap kecamatan diwakili 5 kelompok dan 1 kelomok terdiri dari 5 orang yaitu Ketua, Sekertaris, Bendahara ditambah anggota 2 orang, dengan kriteria Kelompok tani hutan yang telah mengelola hutan rakyat minimal 5 tahun. Penyuluh pertanian 2 orang masing masing 1 orang dari Kecamatan Cenrana dan 1 orang dari Kecamatan Moncongloe. Penyuluh Kehutanan 2 orang, masing masing 1 orang dari Kecamatan Cenrana dan I orang dari Kecamatan Moncongloe. Pemerintah Desa 2 orang, masing masing 1 orang dari salah satu desa di Kecamatan Cenrana dan 1 orang dari salah satu desa di Kecamatan Moncongloe.

\section{Analisis Data}

Sesuai dengan tujuan penelitian, analisis yang digunakan dalam penelitian ini adalah analisis Statistik Deskripif, analisis SWOT (Strength, weakness, opportunity, threat). Arahan strategi pengembangan pengelolaan hutan rakyat dibuat berdasarkan hasil analisis SWOT.

\section{HASIL DAN PEMBAHASAN}

\section{a. Faktor Internal Kekuatan}

\section{Teknik budidaya sederhana}

Berdasarkan hasil wawancara di lapangan diperoleh informasi bahwa tanaman kehutanan terutama Jenis Jati Putih, Sengon, Akasia, Jati Merah, Mahoni, Jabon, Mangga dapat tumbuh dengan baik pada semua wilayah di kabupaten Maros, dan tidak memerlukan perlakuan khusus karena tanaman tersebut termasuk jenis pioneer dan dapat bersaing dengan tanaman lainnya.

\section{Mobilisasi penduduk dan dinamika sosial}

Berdasarkan hasil survey dapat diketahui bahwa pemilik hutan rakyat dengan mudah dapat akses untuk menuju kawasan hutan rakyat, aksessibilitas dan sarana yang menunjang pengembangan hutan rakyat dikabupaten Maros secara umum telah cukup baik. Demikian halnya dengan dinamika social, masyarakat dengan tangan terbuka menerima program pemerintah dan berperan aktif dalam pembangunan hutan rakyat. 


\section{Hasil hutan}

Kehidupan masyarakat khususnya di pedesaan tidak dapat dipisahkan dari hasil hutan baik itu kayu maupun hasil hutan bukan kayu. Peningkatan jumlah penduduk berkorelasi positif dengan kebutuhan akan kayu Oleh karena itu keberadaan hutan rakyat dapat menjadi jembatan antara kebutuhan dan persediaan akan kayu, sehingga masyarakat tidak lagi mengambil kayu kayu alam. Warga masyarakat memanfaatkan kayu dalam membangun rumah, lumbung padi, membuat pondok dan untuk kayu bakar. Saat ini kayu banyak digunakan sendiri oleh masyarakat sebagai bahan membuat rumah salah satunya untuk Plavon, Dinding kamar Rangka Atap, kusen, pintu dan Jendela dan lain lain, selain itu juga untuk kayu bakar.

\section{Nilai ekonomi}

Secara ekonomis usaha kayu rakyat dapat meningkatkan pendapatan petani.Sesuai dengan hasil wawancara para petani umumnya memperoleh tambahan penghasilan sebesar $\mathrm{Rp}$ 150.000 - Rp 200 000/m ${ }^{3}$ setiap kali melakukan transaksi. Jika dalam sebulan mereka mampu menjual $5 \mathrm{~m}$ maka para petani akan memperoleh tambahan penghasilan sebesar Rp $750.000-R p$ 1.000.000. Walaupun angka tersebut belum dapat menggambarkan perolehan keuntungan sesuai usaha dan jerih payahnya, Namun hal ini tentu sangat membantu ekonomi rumah tangga para petani. Pemanfaatan Hutan Rakyat dengan baik tidak hanya dapat meningkatkan pendapatan dan kesejahteraan para pemiliknya, tetapi juga dapat menstimulasi berbagai aktivitas ekonomi sehingga secara simultan dapat meningkatkan kesejahteraan masyarakat.

\section{b. Faktor Internal Kelemahan}

\section{Karakteristi hutan rakyat}

Karakteristik hutan rakyat yang tidak mendukung. Hal ini disebabkan karena karakteristik hutan rakyat di Maros antara lain adalah luas kepemilikan tidak merata, pola kepemilikan beragam, penyebaran areal tidak terkompleks, kelas umur tanaman tidak teratur, pemilik suatu hamparan lahan hutan rakyat dapat berjumlah banyak (Malamassam, 2005). 
Penyebaran yang tidak terkompleks juga memberikan input yang besar dalam proses pemanenan karena memerlukan biaya yang besar dalam proses mengumpulkan kayu hal ini juga seringkali menjadi pertimbangan pelaku industri dan dapat mempengaruhi harga kayu yang dihasilkan.

\section{Informasi pasar masih kurang (Standarisasi Harga Kayu).}

Banyak informasi asimetris yang sampai kepada petani, khususnya yang berkaitan dengan posisi tawar, misalnya harga pohon berdiri, harga kayu dan produk olahannya. Disamping itu biasanya tidak semua informasi diketahui oleh petani, tetapi dikuasai oleh pihak lain. Untuk mendapatkan informasi yang lengkap petani tidak memiliki akses yang cukup, karenanya bantuan dari pemerintah khususnya sangat diperlukan guna memberikan atau menfasilitasi informasi agar sampai kepada petani dan semua pihak terkait guna kemajuan usaha kayu rakyat (Hardjanto 2003). Hal seperti ini juga berlaku di Kabupaten maros dimana informasi yang dimiliki oleh masyarakat khususnya kayu sangat rendah sehingga pedagang pengumpul adalah merupakan pihak yang sepenuhnya menentukan harga kayu.

Menurut Suhardono (2003), perlu diadakan semacam forum temu usaha yang mempertemukan petani, pedagang, dan industri sebagai konsumen akhir sehingga dalam hal tataniaga hasil-hasil dari hutan rakyat, petani tidak berada pada posisi tawar paling bawah dengan demikian diharapkan margin keuntungan yang diperoleh petani dapat bertambah besar.

\section{Strategi pengelolaan}

Rencana strategis pengelolaan pada tingkat petani belum ada.Pengelolaan hutan rakyat di Maros harus diawali dengan penataan areal dan pengaturan produksi yang diterjemahkan kedalam perencanaan jangka panjang, jangka menengah dan tahunan.Perencanaan jangka panjang dibuat untuk setiap Satuan Pengelolaan Hutan Rakyat (SPHR), sedang perencanaan jangka menengah dan jangka tahunan dibuat untuk setiap kelompok tani hutan rakyat. Jika rencana pengembangan ini tidak ada maka pengembangan hutan rakyat ke depan akan dapat berlangsung dengan tidak memperhatikan kelestarian hasil 
dan kelestarian lingkungan yang akan menyebakan tidak adanya kontinuitas peroduksi. Menurut Widayanti (2004), setiap pengelolaan hutan yang berlandaskan atas kelestarian hasil selalu memerlukan pemeliharaan dan peningkatan kualitas tegakan yang memadai. Tebangan tahunan maupun periodik yang dilakukan harus tidak menyebabkan menurunnya potensi hutan namun harus ada upaya peningkatan agar hutan rakyat selalu dalam keadaan penuh. Oleh karena itu dibutuhkan pengetahuan tekhnik silvikultur yang memadai agar rotasi tebangan yang berkesinambungan. Peranan penyuluh dan para pihak sangat penting untuk peningkatan kapasitas keilmuan kelompok tani.

\section{Tingginya ketergantungan petani pada pedagang pengumpul}

Kesulitan yang sering dihadapi oleh petani adalah posisi tawar mereka yang rendah dalam penentuan harga jual. Hal ini dikarenakan kurangnya pengetahuan petani tentang potensi volume kayu dan tentang kualitas kayu.D i samping itu, penjualan kayu oleh petani hanya didasarkan pada kebutuhan yang mendesak menyebabkan petani selalu berada pada posisi tawar yang rendah, karena petani butuh segera mendapatkan uang, sehingga harga jual kayu yang menentukan biasanya tengkulak. Petani tidak memiliki kelembagaan yang kuat dalam memberikan sehingga petani langsung berurusan dengan tengkulak hal tersebut memberikan keleluasaan tengkulak dalam menentukan harga.

\section{Batas kawasan dengan hutan rakyat kurang jelas}

Lokasi hutan rakyat di Kabupaten Maros pada umunya berbatasan dengan kawasan lindung dan hutan produksi terbatas, namun batas antara hutan rakyat dengan kawasan ini banyak yang tidak jelas sehingga terkadang masyarakat menjadi bingung dan mengambil kayu dari kawasan yang berbatasan dengan lahannya. Masyarakat seringkali berbenturan dengan pihak keamanah hutan karena dugaan masyarakat telah melewati areal untuk peruntukan hutan rakyat, hal ini menyebabkan kerisauan dikalangan. 
Faktor Eksternal

a. Faktor Eksternal Peluang (Opportunity)

1. Tersedianya lokasi penanaman berupa lahan kosong.

Hasil survey pada wilayah studi menunjukkan bahwa banyak lahan kosong yang sudah gundul akibat over eksploitasi yakni penebangan dengan sistem tebang habis tanpa diikuti oleh penanaman. Akibatnya lahan-lahan ini menjadi kurus karena humusnya terkikis air di musim hujan sehingga sulit untuk ditanami pohon.

\section{Permintaan Pasar yang memadai}

Berdasarkan hasil survey dapat diketahui bahwa pemilik hutan rakyat dengan mudah dapat menjual kayunya.Hal ini terjadi karena seiring meningkatnya jumlah masyarakat kebutuhan akan kayu juga meningkat dan industry yang bergerak di bidang mebel dengan bahan baku kayu juga berkembang dengan pesat. Hal ini dapat dilihat dengan adanya pedagang pengumpul yang datang membeli kayu kemudian menjualnya, selain itu ada juga bantuan bantuan dari industri penampung dalam pengurusan. Hal ini menunjukkan bahwa kayu masih sangat diminati oleh industri untuk dibeli. Hasil kayu ini dijadikan sebagai bahan baku untuk membuat kayu pertukangan. Mudahnya pemasaran kayu ini merupakan suatu kekuatan dalam pengembangan hutan rakyat.

2. Adanya bantuan bibit dari pemerintah.

Hasil wawancara yang dilakukan dengan pihak pemerintah sendiri memberikan bantuan bibit khususnya yang terkait dalam kegiatan Kebun Bibit Rakyat (KBR) dan Bang Pesona (Pengembangan Perhutanan Sosial Nasional).Pemerintah pusat secara continue memberikan dukungan dalam pembangunan hutan rakyat untuk mengurangi lahan lahan marginal yang tidak produktif baik berupa kebun bibit rakyat maupun bank pesonan, Pembagian bibit ini diharapkan akan memberikan dorongan bagi masyarakat untuk menanam lahan kosong dan kritis yang mereka miliki sehingga kesinambungan hutan rakyat dapat berjalan dengan baik.Kegiatan Kebun Bibit Rakyat dan bank pesona diharapkan dapat memberikan kontribusi terhadap kesejahteraa masyarakat dan juga perbaikan ualitas lingkungan. 
3. Adanya perhatian pemerintah.

Selain program penghijauan yang telah dilakukan bukti lain dari perhatian pemerintah terhadap pengembangan hutan rakyat adalah adanya pemberian insentif yang dapat diberikan berupa pemberian prioritas program-program pembangunan daerah antara lain subsidi, pinjaman lunak, pengaturan, kemudahan pelayanan, dan pendampingan. Pemberian insentif ini bertujuan untuk meningkatkan motivasi pemegang hak dan/atau masyarakat baik secara individu maupun kelompok untuk mempertahankan hutan hak agar tetap berfungsi lindung dan/atau berfungsi konservasi.

\section{Adanya pengembangan peraturan pendukung.}

Peraturan pendukung yang berkaitan dengan hutan rakyat terus dikembangkan oleh pemerintah baik itu pemerintah pusat maupun daerah. Tahun 2016 pemerintah mengeluarkan Peraturan Menteri Kehutanan nomor: P.85/MenLHK/Setjen/ kum.1/II/2016 tentang pengankutan hasil hutan kayu budidaya yang berasal dari hutan hak.Dilain pihak Pemda Provinsi Sulawesi Selatan dengan berdasarkan pada masukan dari berbagai pihak berupa Universitas, LSM dan masyarakat juga terus berusaha mengembangkan peraturan mengenai pengelolaan hutan rakyat.

\section{a. Faktor Eksternal Ancaman (Threat)}

1. Semakin meningkatnya kebutuhan petani

Semakin meningkatnya kebutuhan petani seiring dengan kemajuan teknologi dapat merupakan ancaman terhadap pengembangan hutan rakyat.Ini dapat dilihat dari semakin banyaknya barang-barang produksi industri yang pada awalnya hanya merupakan kebutuhan sekunder kini dianggap oleh petani sebagai kebutuhan primer Kondisi yang demikian akan menyebabkan petani rela menjual kayunya dengan harga yang murah dan pada umur yang masih muda untuk memenuhi tuntutan kehidupan tersebut. Kebutuhan petani yang semakin meningkat dan datangnya lebih awal akan mengakibatkan munculnya sistem ijon dimana petani akan menjual hasil pertaniannya lebih awal dari waktu panen. 


\section{Meningkatnya permintaan kayu dari Formulasi Strategi} pedagang pengumpul.

Meningkatnya permintaan kayu dari pedagang pengumpul dapat juga merupakan suatu ancaman disamping sebagai peluang. Semakin menurunnya produksi kayu dari hutan rimba ini akan mengakibatkan semakin tingginya permintaan kayu yang berasal dari hutan rakyat. Apabila permintaan kayu ini tidak terkendali atau tidak diatur dengan baik maka permintaan ini akan dapat meningkatkan inensitas penebangan tanpa memperhatikan aspek lingkungan hidup sehingga dapat menjadi salah satu Formulasi stategi merupakan tahapan dalam membuat matriks IFAS (Internal Factors Analysis Summary) yang berisi kekuatan dan kelemahan serta matriks EFAS (External Factors Analysis Summary) yang berisi peluang dan ancaman. Hasil evaluasi kedua matriks tersebut kemudian digabungkan yang selanjutnya dengan menggunakan matriks Internal-Eksternal akan dipetakan pengelolaan hutan rakyat dalam suatu diagram untuk mempermudah merumuskan alternatif strategi. ancaman untuk pengembangan Hutan rakyat di masa yang akan datang. 
Tabel 1. Matriks IFAS (Internal Factors Analysis Summary) Pengelolaan Hutan Rakyat di Kabupaten Maros.

\begin{tabular}{|c|c|c|c|}
\hline Faktor Internal & Bobot & Rating & Skor \\
\hline \multicolumn{4}{|l|}{ KEKUATAN : } \\
\hline 1. Teknik budidayanya sederhana & 0.181 & 4 & 0.724 \\
\hline 2. Mobilisasi penduduk dan dinamika sosial & 0.122 & 4 & 0.488 \\
\hline 3. Hasilnya dapat digunakan sendiri olehpemiliknya. & 0.075 & 3 & 0.225 \\
\hline $\begin{array}{l}\text { 4. Nilai Ekonomi cukup baik (secara Financial layak untuk } \\
\text { diusahakan }\end{array}$ & 0.062 & 3 & 0.186 \\
\hline Sub Total & 0.440 & & $\mathbf{1 . 6 2 3}$ \\
\hline \multicolumn{4}{|l|}{ KELEMAHAN : } \\
\hline $\begin{array}{l}\text { 1. Karakteristik hutan rakyat yang tidak mendukung } \\
\text { 2. Rencana strategis pengelolaan pada tingkat petani belum }\end{array}$ & 0.193 & 4 & 0.772 \\
\hline ada & 0.091 & 4 & 0.364 \\
\hline 3. Informasi pasar kurang(Tidak ada standarisasi harga kayu) & 0.151 & 4 & 0.604 \\
\hline $\begin{array}{r}\text { 4. Tingginya ketergantungan petani pada pedagang } \\
\text { pengumpul }\end{array}$ & 0.064 & 3 & 0.192 \\
\hline 5. Batas kawasan dengan hutan rakyat kurang jelas & 0.061 & 2 & 0.122 \\
\hline Sub Total & 0.560 & & 2.054 \\
\hline TOTAL & 1 & & 3.677 \\
\hline TOTAL SKOR KEKUATAN - KELEMAHAN & & & -0.431 \\
\hline
\end{tabular}

Sumber :Data Primer Hasil Analisis

Tabel 2. Matrik EFAS (External Factor Analysis Summary) Pengelolaan Hutan Rakyat di Kabupaten Maros.

\begin{tabular}{|c|c|c|c|}
\hline Faktor Eksternal & Bobot & Rating & Skor \\
\hline \multicolumn{4}{|l|}{ PELUANG : } \\
\hline 1. Adanya bantuan bibit dari pemerintah & 0.151 & 4 & 0.604 \\
\hline $\begin{array}{l}\text { 2. Adanya perhatian pemerintah terhadap pengembangan } \\
\text { hutan rakyat }\end{array}$ & 0.092 & 3 & 0.276 \\
\hline $\begin{array}{l}\text { 3. Adanya pengembangan peraturan pendukung pengelolaan } \\
\text { hutan rakyat }\end{array}$ & 0.067 & 3 & 0.201 \\
\hline 4. Permintaan pasar yang memadai & 0.171 & 4 & 0.684 \\
\hline 5. Tersedianya lokasi penanaman berupa lahan kosong & 0.225 & 4 & 0.9 \\
\hline Sub Total & 0.706 & & 2.665 \\
\hline \multicolumn{4}{|l|}{ ANCAMAN : } \\
\hline 1. Semakin meningkatnya kebutuhan petani & 0.202 & 4 & 0.808 \\
\hline $\begin{array}{l}\text { 2. Meningkatnya permintaan kayu dari pedagang pengumpul } \\
\text { sehingga mengurangi ketersediaan kayu karena penebangan } \\
\text { yang berlebih. }\end{array}$ & 0.092 & 3 & 0.276 \\
\hline Sub Total & 0.294 & & $\mathbf{1 . 0 8 4}$ \\
\hline TOTAL & 1 & & 3.749 \\
\hline TOTAL SKOR PELUANG - ANCAMAN & & & 1.581 \\
\hline
\end{tabular}

Sumber :Data Primer Hasil Analisis

Hasil analisis menunjukkan bahwa 2.054; sedangkan untuk faktor eksternal total skor faktor internal kekuatan adalah peluang 2.665; faktor eksternal ancaman sebesar 1.623; faktor internal kelemahan 1.084. Berdasarkan nilai-nilai ini diperoleh 
posisi strategi pengembangan Hutan rakyat yang lebih baik. Matriks SWOT pada terletak pada sel 3 dengan nilai koordinat (- dapat menghasilkan empat alternatif strategi 0.431 ; 1.581), apabila posisi berada pada yaitu strategi S-O, W-O, S-T dan W-T yang kuadran (sel) 3, maka sebaiknya diterapkan dirumuskan dengan menyesuaikan kekuatan strategi W-O (Weaknes-Oportunity), yaitu dan kelemahan berdasarkan ancaman dan strategi meminimalkan masalah-masalah peluang yang ada. internal sehingga dapat merebut peluang

\begin{tabular}{|c|c|c|}
\hline $\begin{array}{l}\text { FAKTOR } \\
\text { EKSTERNAL }\end{array}$ & 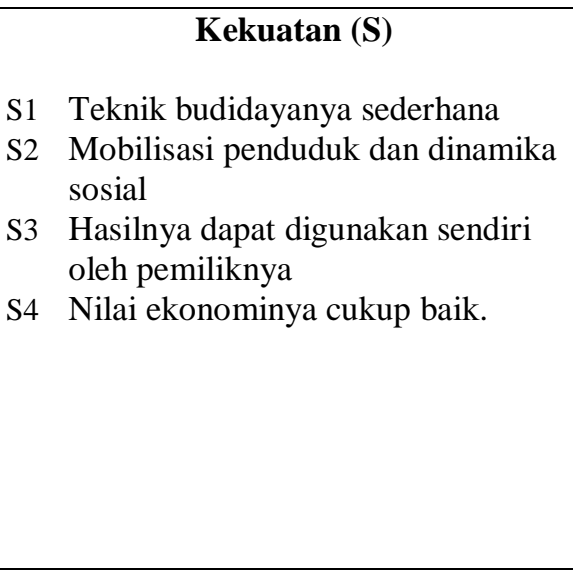 & $\begin{array}{l}\text { W1 Tingginya ketergantungan } \\
\text { petani pada pedagang } \\
\text { pengumpul } \\
\text { W2 } \begin{array}{l}\text { Batas kawasan dengan hutan } \\
\text { rakyat kurang jelas }\end{array} \\
\text { W3 Rencana strategis } \\
\text { pengelolaan pada tingkat } \\
\text { petani belum ada } \\
\text { W4 Informasi pasar kurang(harga } \\
\text { kayu kurang) } \\
\text { W5 Karakteristik hutan rakyat } \\
\text { yang tidak mendukung }\end{array}$ \\
\hline 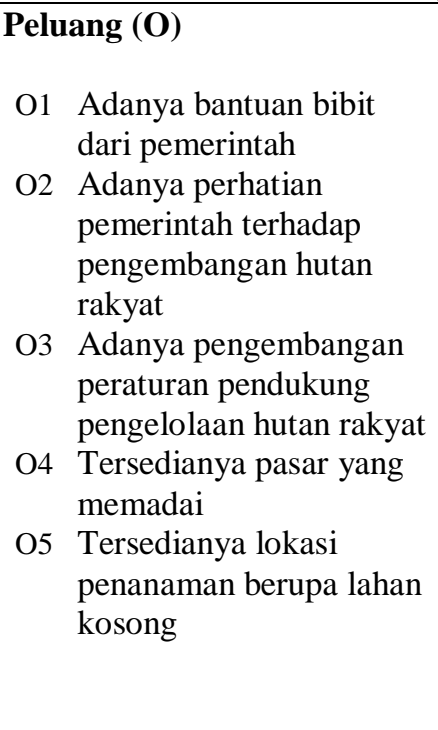 & 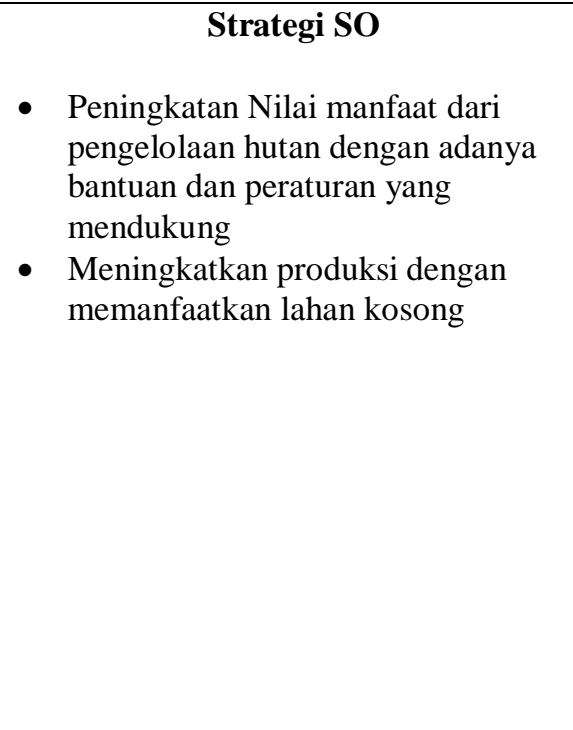 & $\begin{array}{l}\text { - Strategi WO } \\
\text { - } \\
\text { kenguatkan peran dari } \\
\text { kelompok dengan } \\
\text { memberikan informasi pasar } \\
\text { secara akurat. } \\
\text { - } \text { Pemerintah memudahkan } \\
\text { perijinan untuk mendirikan } \\
\text { industri kayu untuk } \\
\text { meningkatkan harga nilai } \\
\text { kayu. } \\
\text { Melakukan penyuluhan } \\
\text { kehutanan dan bimbingan dari } \\
\text { pemerintah untuk penataan } \\
\text { areal kawasan dan } \\
\text { penyusunan rencana } \\
\text { pengelolaan. } \\
\text { Mengunakanpola } \\
\text { agroforestry. }\end{array}$ \\
\hline 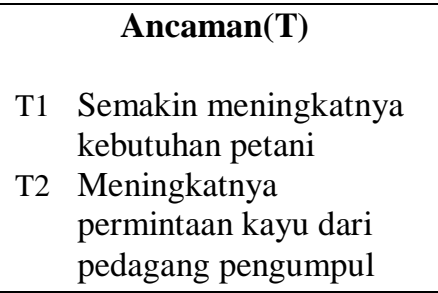 & $\begin{array}{l}\text { Strategi ST } \\
\text { - } \quad \text { Mengembangkan Pola Agroforestry } \\
\text { untuk meningkatkan produktifitas } \\
\text { lahan. } \\
\text { - Melakukan penataan areal untuk } \\
\text { mengatur produksi dan penanam }\end{array}$ & $\begin{array}{l}\text { Strategi WT } \\
\text { - } \quad \text { Meningkatkan pengetahuan } \\
\text { Petani tenang nilai manfaat } \\
\text { hutan baik dari segi ekonomi, } \\
\text { maupun ekologi } \\
\text { - } \quad \text { Melakukan penataan batas } \\
\text { kawasan dengan hutan rakyat }\end{array}$ \\
\hline
\end{tabular}


sehingga mengurangi ketersediaan kayu karena penebangan yang berlebih. dalam rangka menjamin kelestarian hasil

- Membentuk dan meningkatkan peran kelompok / kelembagaan petani.

\section{Kesimpulan}

1. Faktor internal kekuatan meliputi (a) Teknik budidayanya sederhana, (b) Mobilisasi penduduk dan dinamika social, (c) Hasilnya dapat digunakan sendiri oleh pemiliknya, (d) Nilai Ekonomi cukup baik (secara Financial layak untuk diusahakan, sedangkan kelemahannya meliputi (a) Tingginya ketergantungan petani pada pedagang pengumpul (b) Batas kawasan dengan hutan rakyat kurang jelas (c) Rencana strategis pengelolaan pada tingkat petani belum ada (d) Informasi pasar kurang (belum ada standarisasi harga) (e) Karakteristik hutan rakyat yang tidak mendukung.

2. Faktor eksternal yang berpengaruh terdiri atas peluang dan ancaman, dimana variabel peluang meliputi (a) Adanya bantuan bibit dari pemerintah (b) Adanya perhatian pemerintah terhadap pengembangan hutan rakyat (c) Adanya pengembangan peraturan pendukung pengelolaan hutan rakyat
(d)Tersedianya pasar yang memadai (e) Tersedianya lokasi penanaman berupa lahan kosong.

3. Hasil analisis menunjukkan bahwa total skor faktor internal kekuatan adalah sebesar 1.623; faktor internal kelemahan 2.054; sedangkan untuk faktor eksternal peluang 2.665; faktor eksternal ancaman 1.084. Berdasarkan nilai-nilai ini diperoleh posisi strategi pengembangan Hutan rakyat terletak pada sel 3 dengan nilai koordinat $(-0.431 ; 1.581)$, maka sebaiknya diterapkan strategi W-O (Weaknes-Oportunity), yaitu strategi meminimalkan masalah-masalah internal sehingga dapat merebut peluang yang lebih baik.

4. Terdapat dua prioritas strategi yang dapat diterapkan agar Pengelolaan Hutan rakyat di Kabupaten Maros dapat berkembang dengan baik sesuai analisis SWOT dengan urutan tingkatan prioritas strategi yaitu (1) Menguatkan peran dari kelompok dengan memberikan informasi pasar secara 
akurat; (2) Melakukan penyuluhan Malamassam D. 2005.Pengkajian Ulang kehutanan dan bimbingan dari pemerintah untuk penataan areal kawasan dan penyusunan rencana pengelolaan.; (3) Pemerintah memudahkan perijinan untuk mendirikan industri kayu untuk meningkatkan harga nilai kayu; dan (4) Mengunakan pola agroforestry.

\section{DAFTAR PUSTAKA}

Hardjanto. 2001. Dampak Krisis Ekonomi dan Moneter terhadap Usaha Kehutanan Masyarakat : Kayu Jati dan Sengon di Jawa. Resiliensi Kehutanan. Bogor : Institut Pertanian Pemanfaatan dan Pengelolaan Hutan Rakyat di Tana Toraja.Makassar : P3DAS LPPM Unhas

Suhardono. 2003. Pengelolaan Hutan Rakyat di Wonosobo. Jurnal Hutan Rakyat 5(1) : 1-8

Sukadaryati, 2006. Potensi Hutan Rakyat di Indonesia dan Permasalahannya. Puslitbang Teknologi Hasil Hutan

BPS Kabupaten Maros. 2016. Maros dalam Angka. Maros : BPS Kabupaten Maros

Widayanti, T.W. 2004.Implementasi Metode Pengaturan Hasil Hutan pada Pengelolaan Hutan Rakyat (Studi di Desa Kedung Keris, Kecamatan Nglipar, Kabupaten Gunung Kidul). Jurnal Hutan Rakyat $5(3): 1-1$ 